\title{
Modeling Peak Load Reduction and Energy Consumption Enabled by an Integrated Thermal Energy and Water Storage System for Residential Air Conditioning Systems in Austin, Texas
}

\author{
Charles R. Upshaw ${ }^{\mathrm{a}, *}$, Joshua D. Rhodes ${ }^{\mathrm{a}, 1}$, Michael E. Webber ${ }^{\mathrm{a}, 1}$ \\ ${ }^{a}$ Department of Mechanical Engineering, The University of Texas at Austin, 204 E. Dean \\ Keeton St., Stop 2200, Austin, Texas 78712 \\ ${ }^{b}$ Energy Institute, The University of Texas at Austin, 2304 Whitis Ave., Stop C2400, \\ Austin, Texas 78712
}

\begin{abstract}
This paper discusses the development of a model for evaluating peak load reduction and change in overall energy consumption for a residential air conditioning (AC) compressor with and without condenser-side thermal storage. Stored rainwater (or any other type of on-site water storage) could be utilized as a heat sink for the condenser during peak hours, allowing for more efficient and lower power compressor operation, then re-chilled at night during off-peak hours. The system evaluated in this manuscript is referred to as 'Integrated Thermal Energy and Rainwater Storage (ITHERST).

The model used simulated cooling load data for a typical home in Austin, Texas, based on summer 2011 historical and typical meteorological year (TMY) datasets. The analysis suggests that the ITHERST system with 3785-18925 liters of water could reduce on-peak compressor power demand by approximately $29-53 \%$, as compared to a traditional $\mathrm{AC}$ with an air-cooled condenser. However, total compressor energy consumption increases $5-15 \%$ because of the inefficiencies of re-cooling the thermal mass, but this additional energy consumption occurs during low demand off-peak hours. System performance varied depending on weather data, the individual compressor, and thermal storage
\end{abstract}

*Corresponding Author. Email: crupshaw@utexas.edu, Telephone: (512) 589-3056

Preprint submitted to Energy and Buildings

March 23, 2015 
volume.

Keywords: Thermal energy storage, Condenser-side thermal storage, chilled water thermal storage, Residential air conditioning, Peak load reduction, Rainwater collection, Energy-Water Nexus

\section{INTRODUCTION: MOTIVATION AND SCOPE}

\subsection{Motivation: Energy and Water Issues in Texas}

Electricity generation capacity and water resources in Texas are under increasing strain due a variety of factors: a growing population, historic drought, and aging infrastructure [1-4]. The Electric Reliability Council of Texas (ERCOT), the operator of the Texas electricity grid, has expressed concerns about meeting the peak demand in future years while maintaining sufficient reserves [3-5]. There are two primary options for addressing peak demand: 1) build more capacity to generate more electricity, or 2) reduce on-peak demand. The summer peak demand on the ERCOT grid is primarily driven by concurrently operating residential air conditioning (AC) systems during hot summer afternoons. Thus, reducing residential AC load could be a major factor in reducing peak demand $[5,6]$.

One method of reducing peak electricity load for AC systems is to couple the system with an active thermal energy storage (TES) system. For this approach, the thermal mass in a TES system is pre-cooled off-peak so that it can be used on-peak to reduce (or replace) the compressor portion of the AC system by supplementing (or fully meeting) the cooling load [7-10]. While active TES for large commercial HVAC applications is an established industry, there is not yet a market for single-home residential thermal storage systems. Residential TES systems are not yet widely available because of the high capital costs for a dedicated system, and lack of financial incentive for residential peak energy reduction since most residential consumers do not pay time of use rates [11-13]. Pre-cooling the house itself and/or temporarily cycling the air conditioning unit

off can be effective at reducing on-peak load [14], and are the most commonly 
employed methods of reducing residential peak load, but the duration and effectiveness of these methods becomes limited due to increased discomfort on very hot days.

Concurrently, the Texas Water Development Board (TWDB) is also seeking means to increase water availability by: 1) reducing water consumption (e.g. water efficiency measures), and 2) exploring the construction of new water resources [2]. Rainwater collection, a practice that has fallen out of widespread use in Texas and the US, has been one proposed method to, "...generate additional water supplies in Texas...particularly in urban and suburban areas" [15]. One of the current barriers to entry for rainwater collection has been the high capital cost for the system compared to low utility water rates, leading to long payback periods [15-17].

To potentially improve the utility of rainwater collection systems, the stored rainwater could theoretically be used as a thermal storage medium in a residential air conditioning system. This combined system concept, referred to herein as ITHERST (for Integrated Thermal Energy and Rainwater Storage), could potentially increase the economic viability of both residential rainwater collection, as well as residential thermal storage. Since the motivation for this work is to reduce peak electricity demand from residential air conditioning systems in Texas, this model and analysis are focused on residential air conditioning systems. While beyond the scope of this paper, the ITHERST concept could be adapted and implemented in larger scale for commercial buildings, as well as to other types of air conditioning systems (such as chilled water systems).

The hypothesis is that the combined value of on-peak electricity demand reduction and water savings from an ITHERST system will out-weigh the energy penalty and associated equipment costs, especially since redundant parts could be avoided. However, before a full economic analysis can be performed, a thermal system model of an AC system with and without thermal storage is needed to accurately assess system performance over varying real-world conditions. Thus, this analysis attempts to quantify the electric demand reduction and energy penalty portion of that hypothesis. 


\subsection{Rainwater Thermal Energy Storage Literature Review}

The concept of thermal storage is a well-established means of reducing onpeak cooling load and maximizing the cooling system's utilization [7-10]. Likewise, the concept of rainwater collection for reduction of potable water consumption is also well-established [15]. However, the utilization of rainwater for thermal storage has not been a deeply explored topic [18-21]. Below is a summary of relevant literature, and discussion of how the proposed ITHERST configuration and analysis fill a knowledge gap in the literature.

Upshaw et al. 2013 described a conceptualization of the integrated thermal energy and rainwater storage system, as well as the development of a thermodynamic model to estimate system performance based on tank size [18]. In that analysis, the theoretical model assumed the compressor operated as an ideal compressor with a constant $75 \%$ isentropic efficiency [18]. The purely theoretical model provided a first-cut assessment of the concept, but was limited in that it did not capture the real-world inefficiencies of off-design operating conditions. The present analysis describes an updated model that utilizes empirical compressor performance curves to estimate compressor energy consumption, which will be discussed in detail in Section 3. Additionally, while the Upshaw 2013 paper only estimated peak load reduction for a single summer day, this analysis expands the model to calculate the average performance over the entire entire summer.

Kalz et al. 2010 describes the design and experimental testing of a heating and cooling system utilizing rainwater cisterns in a highly efficient German house [19]. The system included two $11 \mathrm{~m}^{3}$ rainwater cisterns as part of a thermo-active building system that uses radiant heating and cooling to maintain building thermal comfort, while a ventilation system provides fresh air [19]. The cooling system is limited to circulation of cold water through the thermo-active building structures, which cools the walls and absorbs heat from the air, which is then deposited in the colder rainwater cistern. The cooling system does not use any sort of air conditioning for space cooling. The cooling system is operated continuously when needed, without cycling or tank re-cooling. Heat 
removal from the tank is limited to the natural heat loss from the tank to the surrounding ground. Gradual warming of the rainwater cistern was an issue; it was noted that, attention has to be paid to the operation of the entire system, since permanent cooling and heating results in a fast depletion of the energy reservoir [19]. The heating mode of the Kalz system uses the rainwater for the heat source for a heat pump, but the system is not actively re-heated [19]. The Kalz paper also identified the relative lack of literature on the topic of utilizing rainwater as a heat source and sink [19].

Gan et al. 2007 describes the simulation and experimental testing of a heat pump coupled to an in-ground rainwater tank with an array of heat exchanger arms for exchanging heat with the surrounding soil [20]. The tank-soil heat exchanger was meant for enhanced thermal interaction between the tank and soil, which allowed for better absorption of heat form the soil during heating operation, and better dissipation of heat to the soil during cooling mode operation. Gan describes the system as an enhancement to normal ground source heat pumps by avoiding costly drilling of deep boreholes to attain a steady ground temperature source [20]. However, their focus in system design was entirely heating; there was no mention of air conditioning or cooling, and their primary concern was the tank freezing [20]. Like the Kalz system [19], the Gan system is a passively recharged system, meaning the rainwater thermal storage is not actively re-charged (re-cooled or re-heated).

While not rainwater or thermal storage, Liu et al. 2013 discusses the modeling and prototype testing of a heat pump with both air and graywater-cooled condenser coils for both space conditioning and water heating [21]. Liu discusses the cooling system performance gains by utilizing the gray water for condenser cooling, but the system is not operated in an active thermal storage manner to maximize peak load reduction [21]. The multifunction gray water source heat pump tested in Liu paper analysis was originally conceived and designed with the goals of reducing overall energy consumption and water consumption, and was first described and modeled in Ni et al. 2012 [22]. This system differs from the ITHERST concept proposed in this paper because it was designed and 
operated for overall energy savings, rather than peak load reduction.

In summary, the present analysis improves and expands upon the concept of using a rainwater as the thermal mass in an active thermal storage system for peak electric load reduction. The ITHERST configuration of the present analysis differs from the the systems described by Kalz and Gan because the primary goal is active, diurnal peak shifting of cooling load, rather than serving as a passive thermal sink to improve heat pump efficiency [19, 20]. Lastly, this analysis addresses some of the limitations of original Upshaw model by increasing the analysis period to the entire summer, as well as incorporating more realistic, empirically-derived performance curves for the compressor [18].

\subsection{Scope}

This analysis of the ITHERST concept is limited to typical residential direct expansion (DX) air conditioning systems. For input to the present analysis, cooling demand for a typical residential building in Austin, TX was modeled based on averaged data from local energy audits [6]. The model was built in BEopt, a building energy modeling software published by the National Renewable Energy Laboratory (NREL) [23]. The BEopt model was executed with 2011 historical data, and typical meteorological year (TMY) data, to obtain simulated house cooling load data. The cooling load data and weather data were then used as input for a MATLAB model, which used bi-cubic empirical compressor curves to estimate the compressor electrical power demand and energy consumption necessary to meet the load (Section 3). The model calculates the power demand and energy consumption for a DX system with and without the thermal storage system. The outputs of the two scenarios were used to calculate comparative performance metrics, such as the average reduction in on-peak power demand, and the overall energy consumption difference (Section 4). 


\section{SYSTEM DESCRIPTION}

\subsection{ITHERST System Operation}

The ITHERST system configuration for this analysis is based on the system described in Upshaw et al. 2013, which is a typical direct expansion AC system with an air-cooled condenser coupled to the water system through a series of reconfigurable valves and a water/refrigerant heat exchanger[18]. Figure 1 shows the basic schematic and operational flow paths of the refrigerant in the THERST system. Note that the schematic does not include auxiliary valves, sensors, and other components for display clarity, but does show both active (top tank) and passive (bottom tank) water/refrigerant heat exchanger configurations. The arrows trace the refrigerant flow during the three modes of operation; the blue represents condensed refrigerant, and the red represents evaporated refrigerant vapor. There are three modes of operation: 1) Air-cooled Condenser Mode (the refrigerant flows along the solid arrow flow path), 2) Thermal Storage Discharge Mode (dashed arrow flow path), and 3) Thermal Storage Recharge Mode (dotted arrow flow path). Figure 1 contains two tanks to represent both passive (natural convection-driven), and active, (pump-driven) options for the water-side tank heat exchanger system.

The system only discharges the thermal storage to pre cool the AC during a period of time in the afternoon, and waits to recharge it until late at night; during all other times, the system operates in air-cooled mode. Assuming the system starts with the TES completely charged, the full cycle of operation is as follows:

Step 1. Air-Cooled Mode (post-recharge): The AC system operates using its normal air-cooled condenser after the TES has been sufficiently cooled from the day before (air-cooled operation nominally beings at 7-9am), and before the on-peak afternoon hours (before 3pm).

Step 2. Thermal Storage Discharge Mode: The AC system operates using the TES water/refrigerant heat exchanger in place of the air-cooled 


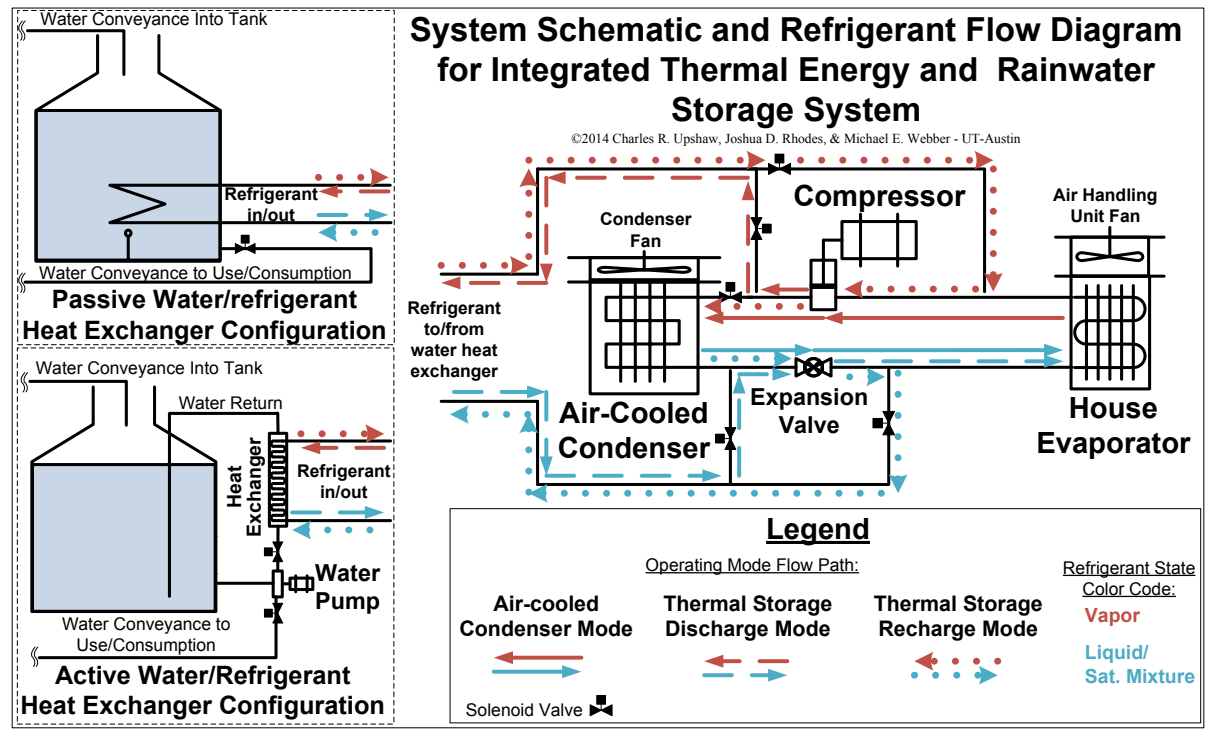

Figure 1: This system schematic demonstrates refrigerant flow directions for the HVAC portion of a proposed integrated thermal energy and rainwater storage (ITHERST) system during its three modes of operation. The arrows trace the refrigerant flow during the three modes of operation; the blue represents condensed refrigerant, and the red represents evaporated refrigerant vapor. The two tanks show both passive (top) and active (bottom) water/refrigerant heat exchanger configurations.

condenser during the on-peak afternoon hours (from 3pm until 7pm, for this analysis), using the pre-cooled water instead of the hot outdoor air as the condenser heat sink. The system discharges either until the on-peak time period is over, or until the maximum allowable tank temperature is reached.

Step 3. Air-Cooled Mode (post-discharge): After the peak period has ended, the AC system returns to using its normal air-cooled condenser for the remainder of evening (7pm until midnight, for this analysis).

Step 4. Thermal Storage Recharge Mode: At midnight, the AC system uses the air-cooled condenser to begin re-cooling the thermal mass instead of cycling the condenser off after meeting the house cooling load. During 
this operation, the $\mathrm{AC}$ directs refrigerant flow to to the house as necessary to meet cooling load, and sends the rest to the water/refrigerant heat exchanger to re-cool the water. The system recharges until either the minimum allowable tank temperature is reached, or until noon (whichever occurs first).

\subsection{Comparison with Traditional TES Systems}

This system configuration differs from traditional chilled water thermal storage systems because the thermal storage is not completely displacing the compressor (or chiller, in the case of a chilled water system), but rather it is used to increase the compressor efficiency by providing a low temperature condenser heat sink. During thermal storage discharge, the refrigerant bypasses the aircooled condenser (which would be cooled with hot outdoor air), and instead is directed to the water/refrigerant heat exchanger, where the cool water provides a much lower refrigerant condensation temperature. Condensation temperature and pressure are dependent variables, and so the reduction in condenser heat sink temperature corresponds to a reduction in condensation pressure, which in turn reduces compressor power demand.

Typical commercial thermal storage systems are incorporated into the chilled water distribution system, allowing TES systems to discharge their stored 'cooling' directly into the cooling water loop [7-10]. The ITHERST system is a 'condenser-side' thermal storage configuration, meaning it is located on the condenser side of the cooling system, and cannot directly provide cooling to be building [8]. A condenser-side storage is not as beneficial as a traditional chilled water or ice TES system for two main reasons: 1) the compressor load is just reduced rather than completely shut off, and 2) the TES absorbs the entire cycle's heat (rather than just the building load), which the AC must then remove off-peak. Since direct expansion systems do not use a intermediate thermal carrier (i.e. chilled water), the compressor cannot be bypassed entirely without interrupting the cooling operation $[8,9]$. However, despite these drawbacks, the ITHERST system could still be very worthwhile overall because it provides a 
means of incorporating active thermal storage into residential (or commercial) DX systems, a currently underserved thermal storage market.

Most efforts to date on active thermal storage for DX systems have focused primarily on ice thermal storage due to its compact footprint and the low condensing temperature ice provides $[10,24-26]$. Additionally, there have been efforts related to incorporating phase change materials into building thermal mass as a form of thermal storage [25, 27, 28]. However, active condenser-side thermal storage using chilled water has not been investigated, especially as part of a larger integrated water/thermal energy storage system, and thus warrants analysis.

Residential air conditioning drives the summer peak electricity load, and current residential $\mathrm{AC}$ demand reduction is limited to utility-controlled system cycling (demand response), where AC systems are cycled off for a portion of time. This ITHERST configuration allows for a significant on-peak power reduction from DX systems, while maintaining full AC operation, which is very desirable on extremely hot days. Additionally, while not part of the analysis here, the ITHERST system provides the additional benefit of reducing potable water consumption through rainwater (and/or other auxiliary water, such as gray water) collection.

The net benefit of this system is non-obvious, and therefore a model was built to assess the magnitude of on-peak power reduction and the associated energy penalty. The following section will describe the ITHERST system model used in this analysis to quantify the power and energy trade-offs.

\section{SYSTEM MODELING}

\subsection{Model Process Framework}

The model used in this analysis is built on a model that was originally developed in Upshaw et al. (2013) [18], but it has been expanded and improved to more accurately capture real-world performance of the compressor at offdesign conditions (Section 3.3). The overall analysis for this paper is based 
on a two-part modeling process, described in Figure 2. The details of each part modeling process are described in Subsections $3.2-3.3$, but generally the modeling process is divided into two steps: 1) generating cooling load data from the BEopt model, and 2) calculating the performance of the air conditioner compressor.

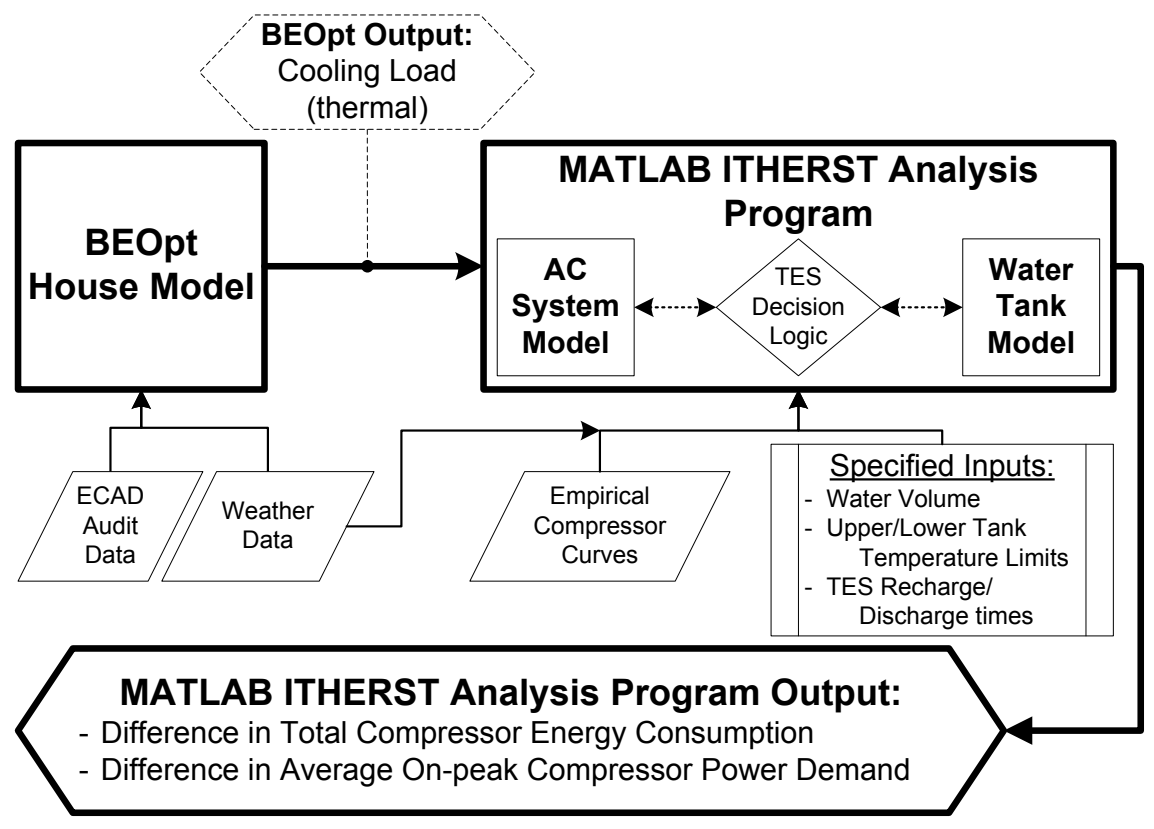

Figure 2: Analysis of the ITHERST system is based on modeled house cooling load data from BEopt, which are fed into a MATLAB program that calculates compressor energy consumption and on-peak power demand with and without TES.

The purpose of this model is to calculate and compare the compressor onpeak power demand and energy consumption of a normal air-cooled DX system to a system equipped with a condenser-connected thermal storage system. This model is not meant to be a detailed simulation of system dynamics, rather the goal is to better estimate nominal system performance to determine whether physical prototyping for real-world experimentation should be pursued. There are some underlying assumptions and specified values inherent in the model, which will be discussed in greater detail in each of the following subsections. 


\subsection{BEopt House Model}

The first part of the modeling process takes house building characteristics and weather data, and uses BEopt to calculate the total thermal cooling load that is met by the air conditioner. BEopt, is a building energy modeling software developed by NREL for the purpose of assessing and optimizing energy retrofits for residential buildings [23]. The energy modeling engine behind BEopt is EnergyPlus, a widely used and vetted building energy modeling software also developed by NREL [29]. As discussed in Section 1.3, Austin ECAD energy audit data were used to generate characteristics for a nominally 'average' Austin single family house. Prior research by the authors has shown BEopt to be a reasonably accurate tool for estimating home energy consumption in Austin homes [30]. The relevant building parameters used in the model are provided in Table A.4 in Appendix A .

Different weather files were used in this analysis to assess performance for historically hot summer weather (actual summer 2011 weather data), and for a typical meteorological year weather (NREL TMY3 weather data). The out-

put of the BEopt model is $\dot{Q}_{l o a d}\left[\frac{k W h \text { thermal }}{h r}\right]$, the total cooling load (sensible and latent thermal energy) that must be removed from the house to maintain the specified temperature setpoint. The cooling load data are then fed into the ITHERST Program (Section 3.3) that calculates the power demand and energy consumption for the AC compressor for each time step over the analysis period using the same outdoor air temperature $\left(T_{o a}\right)$ used in the BEopt model. The ITHERST Program calculates the compressor power demand and energy consumption both with and without thermal storage, and produces performance metrics quantifying the difference. The evaporator coil is operating at the same temperature setpoint in TES discharge mode as it would when operating normally in air-cooled mode, so the same total house load (sensible+latent) is removed when operating in either modes. 


\subsection{ITHERST Program}

\subsubsection{Compressor Power Demand and Cooling Capacity Calculation}

The AC model uses empirically derived compressor performance curves to calculate the compressor power demand and cooling capacity. These empirical curve fits are manufacturer supplied coefficients for standard bi-cubic equations, shown in Equations 1 and 2. Equation 1 calculates the compressor power demand $\left(\dot{W}_{c}[k W]\right)$ based on evaporator and condenser temperatures $\left(T_{e}\left[{ }^{\circ} \mathrm{C}\right]\right.$ and $T_{c}\left[{ }^{\circ} \mathrm{C}\right]$, respectively), with constant coefficients $a_{1}$ through $a_{10}$. Equation 2 calculates the thermal cooling capacity of the air conditioning system $\left(\dot{Q}_{\text {cooling cap. }}[k\right.$ Wthermal $\left.]\right)$, using the same format equation but with different coefficient values (represented by $b_{1}$ through $b_{10}$ ), and also assuming standard sub-cooling and superheating temperature differentials. The coefficients $\left(a_{1}\right.$ through $a_{10}$ and $b_{1}$ through $b_{10}$ ) are empirical, and have units such that the sum of all the equations' components equal $k W$ or $K W_{t h}$, respectively.

$$
\begin{gathered}
\dot{W}_{c}[k W]=a_{1}+a_{2} T_{e}+a_{3} T_{c}+a_{4} T_{e}^{2}+a_{5} T_{e} T_{c} \\
+a_{6} T_{c}^{2}+a_{7} T_{e}^{3}+a_{8} T_{e}^{2} T_{c}+a_{9} T_{c}^{2} T_{e}+a_{10} T_{c}^{3} \\
\dot{Q}_{\text {cooling cap. }}\left[k W_{t h}\right]=0.2928 \times\left[b_{1}+b_{2} T_{e}+b_{3} T_{c}+b_{4} T_{e}^{2}+\right. \\
\left.b_{5} T_{e} T_{c}+b_{6} T_{c}^{2}+b_{7} T_{e}^{3}+b_{8} T_{e}^{2} T_{c}+b_{9} T_{c}^{2} T_{e}+b_{10} T_{c}^{3}\right]
\end{gathered}
$$

These manufacturer-supplied empirical curve fits are generated by controlling the evaporator and condenser temperatures, and measuring corresponding compressor power demand and cooling capacity. The testing method to measure these data are performed according to the ANSI/AHRI Standard 540. This industry-accepted standard requires test results to be within $+-5 \%$, so using these equations to estimate the compressor power demand and cooling capacity provides a realistic estimate of real-world performance [31].

Compressor correlations for five compressors were obtained from two manufacturers $[32,33]$. The compressors chosen were typical of those available in 
residential air conditioning systems, and included both hermetically sealed reciprocating compressors and scroll compressors (both currently available and obsolete models), to provide a range of system types and performances as might be seen in real world. Table B.5 in Appendix B contains a summary of the five compressors selected. The coefficient values for the compressors (for Equations 1 and 2) are provided in Table B.6 in Appendix B. Those compressors that were not rated to exactly $36,000 \mathrm{BTU} / \mathrm{hr}$ were multiplied by an additional re-scaling factor such that their rated capacity would equal 36,000 BTU/hr; this calculation is explained in Equation B.1 in Appendix B. For simplicity, assume all $\dot{W}_{c}$ or $\dot{Q}_{\text {cooling cap }}$ references and values are post-scaling.

For each hourly time step $t$, the compressor model calculates cooling capacity $\left(\dot{Q}_{\text {cooling cap }}\right)$ and compressor power demand $\left(\dot{W}_{c}\right)$ using Equations 1 and 2 , and compares $\dot{Q}_{\text {cooling cap }}$ to the cooling load $\left(\dot{Q}_{\text {load }}\right)$ of the building for that time step. If the calculated cooling capacity calculated is greater than the modeled load for that hour (i.e. $\dot{Q}_{\text {cooling cap }} \geq \dot{Q}_{\text {load }}$ ), then it is assumed the AC system cycled on for a fraction of that hour. As shown in Equation 3, the fraction of time the system is running for a given time step $\left(f_{\text {runtime }_{t}}\right)$ is equal to the fraction of that hourly load for that time step $\left(\dot{Q}_{\text {load }_{t}}\right)$, over the hourly cooling capacity for the same time $\operatorname{step}\left(\dot{Q}_{\text {cooling cap }}\right)$.

$$
f_{\text {runtime }_{t}}=\frac{\dot{Q}_{\text {load }_{t}}}{\dot{Q}_{\text {cooling capt }}}=\left[\frac{k W h_{t h} / h r}{k w_{t h}}\right]=[\text { unitless fraction }]
$$

Conversely, If the cooling capacity calculated is less than the cooling load for a given hour, then the excess thermal load is carried forward and added to the load of the next hour. Equation 4 shows how if $f_{\text {runtime }}$ is greater than 1 for a time step, then the AC system meets a portion of the cooling load equal to the cooling capacity $\left(\dot{Q}_{\text {load }_{t}}=\dot{Q}_{\text {cooling cap }}\right.$ ), and the un-met portion of the load $\left(\dot{Q}_{\text {loadt }}-\dot{Q}_{\text {cooling capt }}\right)$ is added to the cooling load for the next time period. Since the house cooling load is first computed for the entire year, and then the compressor capacity, etc. are calculated in a second step, this forward adjustment helps account for any periods of unmet cooling demands. This rollover is an artifact of the ITHERST Program being a post-process of the BEopt 
model output, rather than a calculation occurring simultaneously within BEopt. The carrying over excess load continues until the cooling capacity is greater than the hourly load, i.e. $f_{\text {runtime }}$ is less than or equal to one. This logic models the air conditioner's inability to remove all of the thermal load from the house during abnormally hot hours, with the unmet energy accumulating in the house contributing to the thermal load in the next hour.

$$
\begin{aligned}
& \text { if: } \\
& f_{\text {runtime }_{t}} \geq 1 \\
& \text { then: } \\
& f_{\text {runtime }_{t}}=1, \text { and } \\
& \dot{Q}_{\text {load }_{t}}=\dot{Q}_{\text {cooling capt }}, \text { and } \\
& \dot{Q}_{\text {load }_{t+1}}=\dot{Q}_{\text {load }_{t+1}}+\left(\dot{Q}_{\text {load }_{t}}-\dot{Q}_{\text {cooling cap }_{t}}\right)
\end{aligned}
$$

The runtime fraction is then used to calculate the total compressor energy consumption $\left(W_{c_{t}}\right)$, the actual cooling load $\left(Q_{\text {cooling }_{t}}\right)$, and the condenser heat load $\left(Q_{\text {cond }_{t}}\right)$ for that time step $t$. The total compressor energy consumption $\left(W_{c_{t}}\right)$ is defined by Equation 5, and states that the energy consumed during each time step is equal to the runtime fraction $\left(f_{\text {runtime }_{t}}\right)$ multiplied by the compressor power demand for that time step $\left(\dot{W}_{c_{t}}\right)$.

$$
W_{c_{t}}[k W h]=\dot{W}_{c_{t}}[k W] \times f_{\text {runtime }}[\text { hours }]
$$

Equation 6 calculates the actual amount of cooling energy used during each time step, and is equal to the available cooling capacity $\left(\dot{Q}_{\text {cooling cap.t }}\right)$ multiplied by the runtime fraction $\left(f_{\text {runtime }_{n}}\right)$.

$$
Q_{\text {coolingt }}\left[k W h_{t h}\right]=\dot{Q}_{\text {cooling cap.t }}\left[k W_{t h}\right] \times f_{\text {runtime }_{t}}[\text { hours }]
$$

The condenser heat load for a given time step $\left(Q_{\text {cond }_{t}}\right)$ is the amount of heat energy rejected through the condenser. $Q_{\text {cond }_{t}}$ is defined in Equation 7 as the sum of the cooling load $\left(Q_{\text {cooling }_{t}}\right)$ and the compressor energy consumption $\left(W_{c_{t}}\right)$. This equation assumes all electrical energy drawn by the compressor is 
ultimately rejected through the condenser in the form of heat.

$$
Q_{\text {cond }_{t}}\left[k W h_{t h}\right]=Q_{\text {cooling }_{t}}+W_{c_{t}}
$$

Equations 1 - 7 capture the total energy flows (both thermal and electrical) in and out of the system for a given time step $t$. These energy flows are used to calculate the TES tank temperature (Section 3.3.3), as well as for assessing overall system efficiency (Section 4.1).

The compressor curves (Equations 1 - 2) allow for the direct computation of compressor power and cooling capacity based on specified evaporating $\left(T_{e}\right)$ and condensing $\left(T_{c}\right)$ temperatures. In this model the evaporator temperature is specified to be $7.2^{\circ} \mathrm{C}\left(45^{\circ} \mathrm{F}\right)$, a common standard cooling coil temperature which accounts for the necessary heat exchanger temperature differential needed to extract heat and moisture (the cooling load) from the building supply air. [9]. The evaporating temperature is assumed to stay constant throughout operation.

The condenser temperature (or temperature at which the refrigerant in the system condenses) is a function of the environmental temperature into which the condenser is rejecting heat - either the outdoor ambient air temperature, $T_{o a}$ (a known, independent variable), or a function of the bulk water temperature in the TES tank, $T_{\text {tank }}$ (a calculated, dependent variable). Additionally, the actual condensing temperature of the refrigerant $\left(T_{c}\right)$ is affected by the heat transfer performance of the condenser heat exchanger, and will necessarily be higher than the condenser environmental temperature (i.e. $T_{\text {oa }}$ or $T_{\text {tank }}$ ) because there must be a thermal gradient for heat to flow [34]. In this model, the details of the condenser heat transfer phenomena are approximated as a condenser 'temperature difference' or 'temperature split' value $\left(T D_{c}\right)$ to approximate the actual condensing temperature based on the known environmental temperature. Equation 8 show the calculation of the condenser temperature $\left(T_{c}\right)$ based on the environment temperature $\left(T_{o a}\right.$ or $\left.T_{\text {tank }}\right)$, and the specified temperature difference $\left(T D_{c, \text { oa }}\right.$ or $\left.T D_{c, \text { water }}\right)$.

$$
\begin{aligned}
& \text { For air-cooled condenser: } T_{c}=T_{o a}+T D_{c, \text { oa }} \\
& \text { For water - cooled condenser: } T_{c}=T_{\text {tank }}+T D_{c, \text { water }}
\end{aligned}
$$


Since heat must have a temperature gradient to flow, the refrigerant condensing temperature must necessarily be some amount higher than the environment temperature around the condenser heat exchanger [34, 35]. Additionally, the heat transfer of a regular air-cooled condenser and a water cooled condenser are typically not the same (because water has more thermal mass and better thermal conductivity), and this change in performance can be accounted for by using different $T D_{c}$ values [34]. As shown in Equation 8, different $T D_{c}$ constants were assumed for the two modes of operation $\left(T D_{c, \text { oa }}\right.$ and $T D_{c}$, water $)$ based on general HVAC rules of thumb. $T D_{c, \text { oa }}$ for the air-cooled condenser mode was assumed to be approximately $16.5^{\circ} \mathrm{C}\left(30^{\circ} \mathrm{F}\right)$, and $T D_{c}$, water for the water-cooled mode (i.e. TES operation) was assumed to be approximately $5.5^{\circ} \mathrm{C}\left(10^{\circ} \mathrm{F}\right)[34,36]$. These are approximations, but are a reasonable and accepted proxy for heat exchanger performance in the absence of heat exchanger and flow details. Table 1 summarizes the input temperature variables that remain constant throughout the analysis, including the evaporator temperature $\left(T_{e}\right)$, the maximum and minimum allowable tank temperatures $\left(T_{\text {tank, max }}\right.$ and $T_{\text {tank, min }}$, Section 3.3.2), and the condenser temperature difference values for both outdoor air and water-cooled operation $\left(T D_{c, \text { oa }}\right.$ and $T D_{c}$, water $)$.

Table 1: Several temperature variables are held constant throughout the analyses. The values provided are in metric units, with the English unit equivalent provided in the parentheses.

\begin{tabular}{cll}
\hline Variable & Value & Units \\
\hline$T_{e}$ & $7.2(45)$ & ${ }^{\circ} \mathrm{C},\left({ }^{\circ} \mathrm{F}\right)$ \\
$T_{\text {Tank min }}$ & $15.6(60)$ & ${ }^{\circ} \mathrm{C},\left({ }^{\circ} \mathrm{F}\right)$ \\
$T_{\text {Tank max }}$ & $23.8(75)$ & ${ }^{\circ} \mathrm{C},\left({ }^{\circ} \mathrm{F}\right)$ \\
$T D_{c, \text { oa }}$ & $16.5(30)$ & ${ }^{\circ} \mathrm{C},\left({ }^{\circ} \mathrm{F}\right)$ \\
$T D_{c, \text { water }}$ & $5.5(10)$ & ${ }^{\circ} \mathrm{C},\left({ }^{\circ} \mathrm{F}\right)$ \\
\hline
\end{tabular}




\subsubsection{TES Control Logic}

The ITHERST program first calculates the compressor power demand and energy consumption for the specified time span using air-cooled operation only. Next, the model begins using the TES logic to control the discharging and recharging of the thermal mass. The on-peak period during which the system discharges the thermal storage (uses water to cool the condenser) is 15:00 until 19:00, or until $T_{\text {tank max }}$ is reached. The on-peak range was chosen because it covers the same time of day as the the Austin Energy Commercial Thermal Storage rate (which requires TES operation 15:30pm - 18:30pm), but is extended by 30 minutes before and after to be compatible with the 'on-the-hour' hour time step used in the model [37]. Between 19:00 and 24:00 (midnight), the system operates on the air-cooled mode only, without discharging or recharging the TES. After midnight, the system begins to recharge the thermal mass using spare cooling capacity; this recharge operation continues until the tank

temperature reaches $T_{\text {tank } \min }$. For this analysis, $T_{\text {tank min }}$ was chosen to be $15.6^{\circ} \mathrm{C}\left(60^{\circ} \mathrm{F}\right)$, and $T_{\text {Tank max }}$ was chosen to be $23.8^{\circ} \mathrm{C}\left(75^{\circ} \mathrm{F}\right)$. This temperature range was chosen because it is sufficiently low to provide a significant boost to performance during the entire TES discharge, but not so low as to require a change in evaporating temperature when recharging the system.

\subsubsection{TES Water Tank Temperature Calculation}

Since the focus of this analysis are the thermal storage aspects of ITHERST, the water tank model only calculates the temperature change in the water based on the thermal inputs and outputs supplied by the cooling model. The tank is assumed to be well insulated (adiabatic) and the water volume is kept constant (e.g. assuming a certain volume in the tank is reserved specifically for TES). The tank temperature calculation is a lumped capacitance thermal model, shown in Equation 9.

$$
T_{\text {Tank } t_{f}}=\frac{Q_{\text {cond }_{t}}}{\rho C p_{\text {water }} V_{\text {tank }}}+T_{\text {Tank } t_{i}}
$$

Equation 9 calculates the final water temperature for the time step $\left(T_{T_{a n k} t_{f}}\right)$ from the thermal load being rejected into the tank $\left(Q_{\text {cond }_{t}}\right)$ for that time step, 
the thermal mass of water in the tank $\left(\rho C p_{\text {water }} V_{\text {tank }}\right)$, plus the initial water tank temperature for the time step $\left(T_{\text {Tank }} t_{i}\right)$. In this equation, $\rho$ is the density of water, $C p_{\text {water }}$ is the specific heat for water, and $V_{\text {tank }}$ is the volume of water in the tank. The model calculates $T_{\text {Tank } f_{t}}$ based on the input water property parameters and starting tank temperature for each time step, and then $T_{\text {Tank } t_{f}}$ becomes the beginning temperature for the following time step (i.e. $T_{\text {Tank } t_{f}}=T_{\text {Tank } t+1_{i}}$ ).

The compressor and cooling portion of the model use an average of $T_{\text {Tank }} t_{i}$ and $T_{\text {Tank } t_{f}}$ plus $T D_{c}$, water as the $T_{c_{t}}$ when discharging the thermal storage system. During the peak hours (and assuming the $T_{\text {tank max }}$ has not been exceeded), heat is rejected from the AC system into the tank, raising the tank temperature. Since the condenser heat load $\left(Q_{\text {cond }_{t}}\right)$ going into the tank is dependent on the compressor energy consumption $\left(W_{c_{n}}\right)$, and compressor energy consumption is dependent on the tank temperature (due to the temperaturedependent efficiency of the compressor), the solution is iteratively determined. The model iterates to a solution by assuming a condenser load, calculating the ending temperature based on that load, and then recalculating condenser load based on the new average tank temperature. At night, when the system is operating in recharge mode (Step 4), the tank condenser acts as the evaporator. Heat is removed from the tank by reconfiguring valves and using the water/refrigerant heat exchanger as an evaporator, and the air-cooled condenser rejects the heat to the atmosphere. Equation 9 is still valid if the heat 'input' to the water tank

$\left(Q_{\text {cond }}\right)$ is negative (i.e. during Step 4 when the system is recharging), with the result being a decrease in $T_{\text {Tank } t_{f}}$ rather than an increase.

\subsection{Summary of Simplifying Assumptions}

The model is a simplified, steady-state representation of an air conditioning system and water tank. The model does not capture the impact of heat transfer characteristics in the evaporator and condenser. For simplification, it was assumed that the $T_{e}$ is specified as a known constant. The outdoor air temperature and $T_{o a}$ are is variable, but known for all time periods. The con- 
denser temperature difference values $\left(T D_{c, \text { oa }} T D_{c}\right.$, water $)$ are assumed to be independent, constant variables. The assumptions chosen for the evaporator were based on standard HVAC approximations for sizing calculations [9], and the condenser temperature difference values were based on standard industry assumptions $[34,36]$. It was assumed that the heat will dissipate quickly enough into the bulk of the fluid that the local condenser temperature in the condenser heat exchanger and the average bulk temperature are approximately equal. To summarize, the major simplifying assumptions made in the model include:

- The condensation temperatures are assumed to be equal to the environment they are in (i.e. the outdoor air temperature or the bulk tank temperature), plus a constant $T D_{\text {cond }}$ offset dependent on the environment.

- The evaporation temperature is assumed to be a constant $7.2^{\circ} \mathrm{C}\left(45^{\circ} \mathrm{F}\right)$, regardless of time, cooling load, or condenser mode [9].

- On-peak period (when TES tank is discharged) is 15:00-19:00, recharge begins at midnight and runs until it recharges (or until noon). All other times the system operates in air-cooled mode.

- The system is adiabatic and does not suffer any parasitic heat gains or losses (e.g. a well insulated tank, out of direct sunlight).

- The water is assumed to uniformly heat from the initial temperature to final temperature within each time step.

- The tank is assumed to be perfectly insulated from the environment, with no parasitic heat losses or gains.

- The evaporating temperature in the tank heat exchanger during thermal recharging is assumed to be treated the same as the normal indoor evaporator. 


\section{ANALYSIS METHODOLOGY}

\subsection{System Performance Metrics}

Using the compressor power demand and energy consumption data calculated in the ITHERST model, the performance of the system was analyzed using two main parameters: 1) peak load reduction (PLR), and 2) energy consumption difference (ECI).

Peak load reduction (PLR) is the difference between on-peak power demand from the AC compressor for regular air-cooled only operation $\left(\dot{W}_{c, r e g_{t}}\right)$ and TES operation $\left(\dot{W}_{c, T E S_{t}}\right)$, averaged over the on-peak hours for the entire model run. Calculation of PLR can be represented as the magnitude of $\mathrm{kWs}$ reduced $\left(P L R_{k W}\right)$, or as a percentage of the air-cooled only case $\left(P L R_{\%}\right)$; the calculations for these parameters are shown in Equations 10 and 11.

$$
\begin{gathered}
P L R_{k W}=\operatorname{Average}\left(\dot{W}_{c, r_{e} g_{t}}-\dot{W}_{c, T E S_{t}}\right)_{\text {on peak }} \\
P L R_{\%}=100 \times \operatorname{Average}\left(\frac{\dot{W}_{c, r e g_{t}}-\dot{W}_{c, T E S_{t}}}{\dot{W}_{c, r e g_{t}}}\right)_{\text {on peak }}
\end{gathered}
$$

The averaging of the equation occurs based on the number of on-peak periods contained within the model run time span. This means that a single day simulation yields the actual $P L R_{k W}$ and $P L R_{\%}$ for that day, but a model executed over the entire summer yields PLR values that are the average of each days' PLR.

Energy consumption increase (ECI) is the difference in the sum total of all energy consumed by the TES-equipped system $\left(\left[\sum_{t=0}^{j} W_{c_{t}}\right]_{T E S}\right)$ versus the regular AC system $\left(\left[\sum_{t=0}^{j} W_{c_{t}}\right]_{r e g}\right)$ over the duration of the simulation. Like the PLR, ECI can be calculated in both a magnitude (total $\mathrm{kWh}$ difference), as well as a percent difference of the TES system energy consumption compared to the base case. Equations 12 and 13 show the calculation of $E C I_{k W h}$ and $E C I_{\%}$ using the summed compressor energy values. 


$$
\begin{gathered}
E C I_{k W h}=\sum_{t=0}^{j} W_{c, T E S_{t}}-\sum_{t=0}^{j} W_{c, r e g_{t}} \\
E C I_{\%}=100 \times \frac{\left[\sum_{t=0}^{j} W_{c_{t}}\right]_{T E S}-\left[\sum_{t=0}^{j} W_{c_{t}}\right]_{r e g}}{\left[\sum_{t=0}^{j} W_{c_{t}}\right]_{r e g}}
\end{gathered}
$$

Where $\left[\sum_{t=0}^{j} W_{c_{t}}\right]_{T E S}$ is the sum total of compressor energy consumption for the TES-equipped system, and $\left[\sum_{t=0}^{j} W_{c_{t}}\right]_{r e g}$ is the sum total of compressor energy consumption for the regular AC system. The compressor power output from Equation 5 is summed for each time step over which the model was run (from $t=0$ to $t=j$ ) for both regular and TES operation.

The PLR and ECI metrics were used to compare the difference in model outputs between the TES and the regular AC system operation. The PLR metrics provide a means to assess average on-peak load reduction as predicted by the model, while the ECI metrics quantify the impact on overall energy consumption from using the thermal storage system. For this analysis, the PLR and ECI discussed in the results will be the average of the individual PLR and ECI calculated for each of the five modeled compressors.

\subsection{Analysis Periods}

The model was run using the time period 12:00 am June 1 through 11:00 am October 1, but different weather files were used to estimate and compare the performance for an abnormally hot year and a typical year. This date range was chosen because Austin Energy defines their summer season as June 1st through September 30th for rate purposes. The model runs start at midnight, and end at 11:00 am because the model starts with the TES fully charged, and thus the additional morning allows for matched charge/discharge cycles.

The first analysis, June 1st - October 1st for 2011, was the hottest summer on record in Austin. The historical weather data were obtained from Weather Analytics [38]. The second analysis consisted of running the model 
using the same summer time period, but using NREL's Typical Meteorological Year (TMY) dataset for Austin [39]. The TMY datasets are compiled by NREL to have statistically 'typical' weather conditions, although they are compiled from actual historical weather [39].

\section{ANALYSIS RESULTS AND DISCUSSION}

System performance was modeled using the full-summer data sets described, iterating through the empirical compressor models (Section 3.3), as well as a range of TES water tank volumes. The model was run assuming the following water tank volumes: no tank (reference case-normal air-cooled condenser operation), 3785 liters (1000 gallons), 7570 liters (2000 gallons), 11355 liters (3000 gallons), 15140 liters (4000 gallons), and 18925 liters (5000 gallons). The focus of the following discussion will be the $P L R_{\%}$ and $E C I_{\%}$ values, since they are normalized and could be reasonably extrapolated to system sizes other than the 3 ton system used for this analysis, assuming different sized compressors operate in a similar, proportional fashion. The $P L R_{k W}$ and $E C I_{k W h}$ are also provided to contextualize the magnitude of the values on which the $P L R_{\%}$ and $E C I_{\%}$ are based.

\subsection{June 1st-September 30th, 2011 Model Results}

The model was run for the Austin Energy-defined summer season, which provided a whole-summer average performance estimate. Since summer 2011 was the hottest on record, this model run represents a 'best case scenario' in terms of expected peak load reduction from the ITHERST system. Table 2 contains the averaged whole-summer PLR and ECI outputs from the five empirical compressor models for this analysis period. These averaged values provide a nominal magnitude for ITHERST system performance over a summer season for a typical Austin house.

The modeled 2011 whole-summer performance averages predict thermal storage would achieve a peak load reduction $\left(P L R_{\%}\right)$ of approximately $40.3-44.8 \%$, 
Table 2: Modeled 2011 whole-summer performance averages (summer season is June 1st Sept. 30th) suggest the ITHERST system would have reduced compressor peak electricity load by $40.3-44.8 \%\left(P L R_{\%}\right)$, with an energy penalty $\left(E C I_{\%}\right)$ of $6.5-8.1 \%$ over the reference case (added energy consumption occurs off-peak).

\begin{tabular}{cllll}
\hline \multicolumn{5}{c}{ Average of Empirical Compressor Models } \\
Tank Size [liters] & $E C I_{\%}$ & $E C I_{k W h}$ & $P L R_{\%}$ & $P L R_{k W}$ \\
\hline Ref. Case & - & 4507 (tot.) & - & 3.27 (tot.) \\
3785 & 8.1 & 366 & -40.3 & -1.32 \\
7570 & 7.1 & 323 & -43.3 & -1.41 \\
11355 & 6.8 & 307 & -44.2 & -1.44 \\
15140 & 6.6 & 299 & -44.6 & -1.46 \\
18925 & 6.5 & 295 & -44.8 & -1.46 \\
\hline
\end{tabular}

with an average energy penalty $\left(E C I_{\%}\right)$ of approximately $6.5-8.1 \%$ over the reference case, depending on the TES volume. The thermal mass of stored water in the ITHERST increases efficiency of the compressor (compared to the air-cooled system) by providing a much lower condensing temperature for the refrigerant, reducing peak load. The roundtrip inefficiencies associated with the storage operation cause higher overall electricity consumption than if operated with the air-cooled condenser only, but this added consumption occurs during the low demand hours at night when prices are lower. This trade-off of peak load reduction for increased overall consumption is typical in commercial TES systems $[7,8]$.

While the averages of the five compressors provide an approximate magnitude of performance, there is significant variation in modeled performance from the five compressors, as shown by the plots of individual compressor $P L R_{\%}$ and $E C I_{\%}$ values compared to the average in Figure $3(\mathrm{a})$ and (b).

The average $P L R_{\%}$ performance for the five compressors is on the order of 40-45\%, but as seen in Figure 3(a) the overall range of compressor performance 

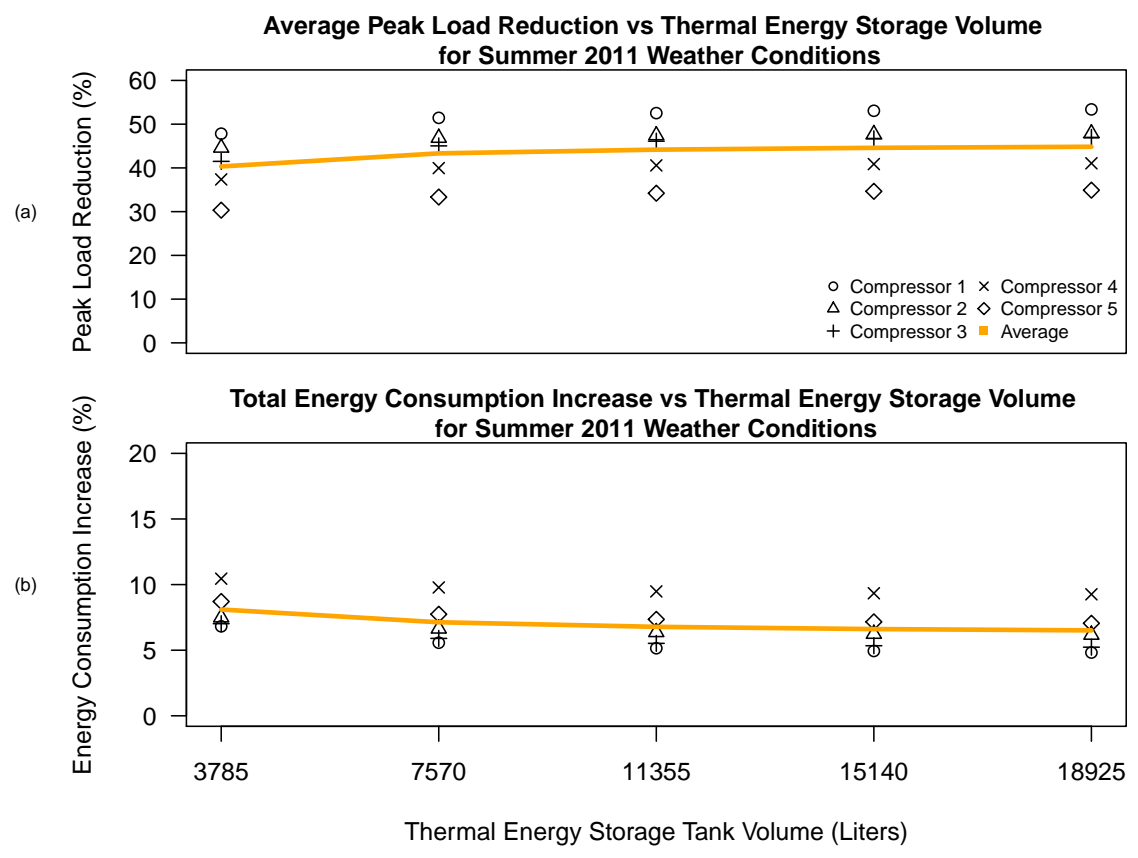

Figure 3: (a) The peak load reduction (PLR) performance of the thermal storage is more heavily impacted by the individual compressor than the volume of thermal storage. (b) The compressors with lower PLR values tend to consume more energy than those with higher values because their poorer performance on-peak leads to more thermal energy that must be removed from the TES volume off-peak.

extends from approximately $30 \%-35 \%$ on the low end to over $48-53 \%$ on the high end. Likewise seen in Figure 3(b), the individual $E C I_{\%}$ for each compressor follows the same nominal trend as the average, but there is a comparatively larger difference between individual compressors. While these compressors are not an exhaustive distribution of compressors currently available, they do demonstrate that individual system performance is heavily dependent on the compressor, and more impactful on overall system performance than the size of the TES volume.

While there are relative performance gains from increasing tank size, the marginal gains diminish quickly. Comparing the 3785 liters systems to the 18925 
gallon systems, the total increase in the performance is $4.5 \%$ (on average), but most of the increase happens in the smallest two tank sizes that were evaluated. Increasing from 3785 to 11355 liters increases the $P L R_{\%}$ by $3.9 \%$; increasing from 11355 to 18925 liters increases $P L R_{\%}$ only by about $0.6 \%$. The trend in performance based on tank size is similar for all of the compressor models, although the actual values differ for each compressor. While not part of this analysis, these results suggest there is likely a tank size that optimizes the cost/performance trade-off.

\subsection{June 1st-September 30th, TMY3 Model Results}

To contrast the historically hot summer, the model was run for the same June 1st - October 1st timespan, but using TMY weather data for Austin. Since TMY weather data are curated to represent a 'typical' year, the TMY model run performance provides a reasonable benchmark for system performance under typical conditions. The output from the TMY3 model run is shown in Table 3.

Table 3: The model suggests the thermal storage system would still provide significant reduction of compressor power demand on less hot summer days, but with slightly lower peak load reduction and more energy consumption.

\begin{tabular}{cllll}
\hline \multicolumn{5}{c}{ Average of Empirical Compressor Models } \\
Tank Size [liters] & $E C I_{\%}$ & $E C I_{k W h}$ & $P L R_{\%}$ & $P L R_{k W}$ \\
\hline Ref. Case & - & 2861 (tot.) & - & 3.03 (tot.) \\
3785 & 12.4 & 355 & -37.2 & -1.13 \\
7570 & 11.4 & 326 & -39.3 & -1.19 \\
11355 & 11.0 & 317 & -40.0 & -1.21 \\
15140 & 10.9 & 313 & -40.3 & -1.22 \\
18925 & 10.8 & 310 & -40.5 & -1.23 \\
\hline
\end{tabular}

As expected, the benefits of the ITHERST system compared to the reference case for TMY model run (Run 2) are not as good as the that for summer 2011 model run (Run 1). The model estimates the system would provide an average 
$P L R_{\%}$ on the order of $37.2-40.5 \%$ for Run 2 , a decline of approximately $3-$ $4 \%$ in the overall peak reduction from Run 1 (and about a relative decline of about $10 \%$ ). The $E C I_{\%}$ increases from $6.5-8.1 \%$ (Run 1) to a range of approximately $11.1-12.4 \%$ (Run 2), a significant increase in relative terms. The performance of the individual compressor model runs are similarly lower than their corresponding 2011 values, as shown by the $P L R_{\%}$ and $E C I_{\%}$ plots in Figure 4(a) and (b), respectively.

(a)

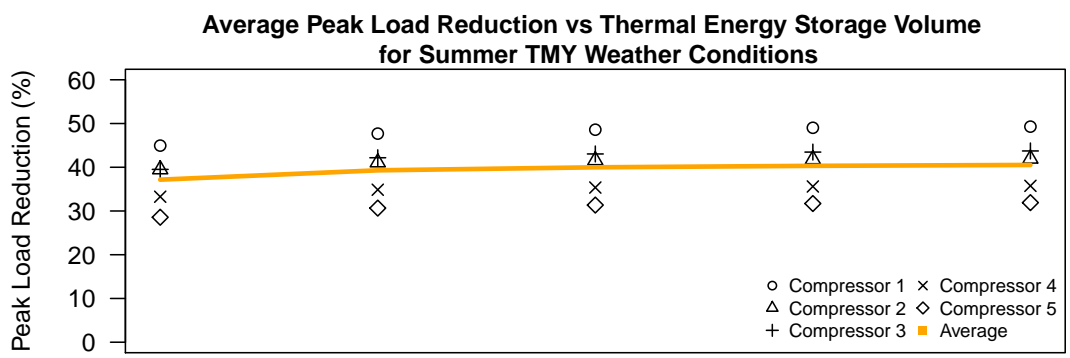

(b)

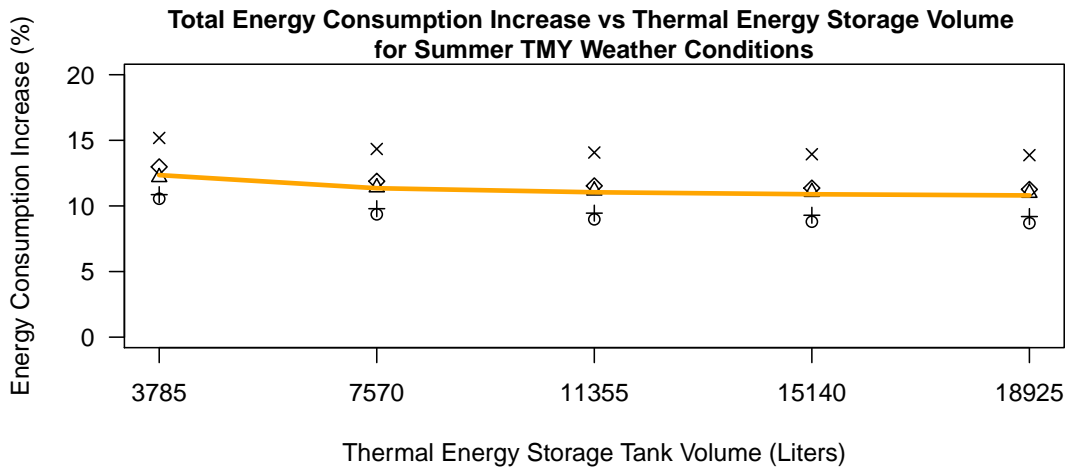

Figure 4: (a) The peak load reduction (PLR) performance of the thermal storage is more heavily impacted by the individual compressor than the volume of thermal storage. (b) The compressors with lower PLR values tend to consume more energy than those with higher values because their poorer performance on-peak leads to more thermal energy that must be removed from the TES volume off-peak.

As shown in Figure 4(a), there is still the same trend of modestly increasing performance with TES volume, and the wide range in performance between compressors, but the $P L R_{\%}$ magnitudes decreased across the board by approx- 
imately $3-5 \%$ between Run 1 and Run 2. Figure 4(b) demonstrates a corresponding shift up for all of the $E C I_{\%}$ values.

The decrease in peak load reduction and increase in total energy consumption is likely due to a lower difference between day and night temperatures in the TMY data than those experienced during summer 2011. A lower temperature differential between on-peak discharging times and off-peak recharging times leads to relatively more round-trip losses because the system is not operating at as significantly different efficiencies when discharging vs. recharging. Regardless, if the goal of the system is to reduce on-peak energy consumption while maintaining full operation, the TMY model results suggest that this system is still reasonably useful. Again, the relative performance gains of increasing tank size are measurable, but diminish quickly with size.

\subsection{Discussion of Results}

For performance context, the peak load reduction of the ITHERST systems can be compared with Austin Energy's (Austin, TX municipal electric utility) residential AC direct load control (DLC) 'Free Thermostat' program. Residential DLC systems decrease the air conditioner electricity load typically by either directly turning the compressor off, or by adjusting the thermostat set point temperature up by several degrees to cause the system to cycle off. Until 2012, Austin Energy's Free Thermostat program provided free thermostats to participants, and in exchange Austin Energy could send a radio-frequency signal to the thermostat that turns off the compressor for a short period of time (15 minutes) during peak load events (typically 2 hours in duration) [14]. Austin Energy's Free Thermostat program had approximately 90,000 customers enrolled at its peak, and realized a peak load reduction of approximately $1.4 \mathrm{~kW}$ per customer per event [40]. This reduction is of the same order of magnitude of the $P L R_{k W}$ as estimated by the ITHERST model, which ranged from $1.1-1.2 \mathrm{~kW}$ for the TMY model run up to 1.3-1.4 for the 2011 model run (column 4 of Tables 2 and $3)$.

Since the air conditioner is being turned off, the Austin Energy DLC program 
can only cycle off a subset of the total participants at a time, rotating the DLC from one group to another to keep houses from over-heating, while also prolonging the duration of load reduction. For the DLC control program, a single house's peak load reduction is averaged among other homes that were not cycled off, leading to averaged load reduction values that are a fraction of that single house's load reduction. In contrast, the peak reduction from the ITHERST system occurs while the system is running at full capacity, without a disruption in cooling or thermal comfort-a significant benefit over traditional DLC options.

This comparison only relates to the magnitude of peak load reduction, and does not take into account the relative costs of each type of reduction measure, but future work will delve into this topic.

\section{CONCLUSIONS AND FUTURE WORK}

The purpose of this analysis was to model and assess the ITHERST system performance over the June 1 to October 1 time span, using five empirical compressor models and a range of 3785-18925 liters of water for TES volume. This

model, while still simplified, provides a reasonable order of magnitude estimate of system performance over a full summer season. Future work will focus on addressing the tank and exchanger heat transfer assumptions to better reflect real-world losses and variability, including thermal gains and losses from the water tank, evaporative losses, as well as water collection and consumption. Ultimately, this improved model will be used to design and size an lab-scale system, which can then be used for experimentally validating and tuning the model.

The model was run using summer 2011 historical data for each of the five compressors modeled, and the resulting average peak load reduction $\left(P L R_{\%}\right)$ was approximately $40-45 \%$ of the reference case, while the average energy consumption difference $\left(E C I_{\%}\right)$ was $6.5-8.1 \%$ greater than the base case. Summer 2011 was the hottest summer on record in Texas, and represents an approx- 
imate upper-bound on summer-long performance. The TMY model analysis showed that a more typical performance would be lower than that for summer 2011 , with an average $P L R_{\%}$ on the order of $37-40 \%$ and an average energy penalty of approximately $11-12 \%$. The TMY model results represent a reasonable estimate of a typical system's performance for any given year, and provide a benchmark for future analyses, comparisons with other modeled systems, and also a target for future prototyping.

Increasing tank size leads to measurable, but quickly diminishing, relative performance gains. The more important system component variable for performance is the individual compressor. Future work will incorporate cost information on system components, and determine an optimal system configuration based on cost/performance criteria.

The modeled $P L R_{\%}$ values suggest that ITHERST type thermal storage could yield peak load reductions similar to those in residential DLC programs, except with the air conditioner maintaining operation rather than being cycled off. Future work will compare the costs/benefits of the two types of residential air conditioning load management.

Rainwater (or graywater, etc.) collection, while not part of this analysis, is a central facet of the ITHERST system design. Future work will develop and integrate a water capture and consumption model to manage the water flows into, and out of, the tank. The water flows model (along with associated equipment costs, water rates, and other relevant parameters) will be incorporated with this thermal storage model and used to develop and integrated system design optimization program to find the overall optimal system design based on both electricity and water cost/performance criteria.

\section{Acknowledgments}

This work was made possible through funding provided by Pecan Street Inc. as part of the Pecan Street Smart Grid Demonstration Project Grant from the Department of Energy. 


\section{Disclosure of Affiliation}

In addition to research work on topics generally related to energy systems at the University of Texas at Austin, the authors are equity partners in IdeaSmiths LLC, which consults on topics in the same areas of interest. The terms of this arrangement have been reviewed and approved by the University of Texas at Austin in accordance with its policy on objectivity in research.

\section{References}

[1] A. S. Stillwell, C. W. King, M. E. Webber, I. J. Duncan, A. Hardberger, The Energy-Water Nexus in Texas, Ecol. Soc. 16 (1).

URL http://www.ecologyandsociety.org/vol16/iss1/art2/

[2] Texas Water Development Board, Water for Texas, Tech. rep., Tesxas WaterDevelopment Board (2012).

[3] S. Newell, K. Spees, J. Pfeifnberger, R. Mudge, M. DeLucia, R. Carlton, ERCOT Investment Incentives and Resource Adequacy, Tech. rep., The Brattle Group (2012).

[4] ERCOT, Report on the Capacity, Demand, and Reserves in the ERCOT Region - February 2014 (2014).

[5] T. Doggett, Ercot Challenges and Opportunities (2013). URL http://www . ercot. com/content/news/presentations/2014/ChallengesOpportunities-Mar 2013.pdf

[6] J. D. Rhodes, B. Stephens, M. E. Webber, Using energy audits to investigate the impacts of common air-conditioning design and installation issues on peak power demand and energy consumption in Austin, Texas, Energy Build. 43 (11) (2011) 3271-3278.

[7] M. A. R. Ibrahim Dincer, Thermal Energy Storage : Systems and Applications, Wiley, 2010. 
[8] L. B. Hyman, Sustainable Thermal Storage Systems: Planning, Design, and Operations, McGraw-Hill, 2011.

[9] ASHRAE, 2009 ASHRAE Handbook - Fundamentals, ASHRAE, 2009.

[10] 2008 ASHRAE Handbook: HVAC Systems and Equipment.

[11] K. Roth, R. Zogg, J. Brodrick, Cool Thermal Energy Storage, ASHRAE J. (2006) 94-96.

[12] A. Arteconi, N. J. Newitt, F. Polonara, State of the Art of Thermal Storage for Demand-Side Management, Appl. Energy 93 (2012) 371-389.

[13] R. Willis, B. Parsonnet, Energy Efficient TES Designs for Commercial DX Systems, ASHRAE Trans. 116 (2010) 147-156.

[14] Dsm performance measures, fiscal year 2010-2011 final report, Tech. rep., Austin Energy (2011).

[15] Texas Water Development Board, Rainwater Harvesting Potential and Guidelines for Texas Report to the 80th Legislature, Tech. Rep. November, State of Texas Rainwater Harvesting Evaluation Committee (2006).

[16] R. Roebuck, R. Ashley, Predicting the hydraulic and life-cycle cost performance of rainwater harvesting systems using a computer based modelling tool This paper describes the development of a computer based modelling and assessment tool for rainwater harvesting ( RWH ) systems, Water Pract. Technol. 2 (2). doi:10.2166/WPT.2007046.

[17] S. Ward, F. a. Memon, D. Butler, Rainwater harvesting: modelbased design evaluation., Water Sci. Technol. 61 (1) (2010) 85-96. doi:10.2166/wst.2010.783.

URL http://www.ncbi.nlm.nih.gov/pubmed/20057094

[18] C. R. Upshaw, J. D. Rhodes, M. E. Webber, Modeling A Combined EnergyWater Storage System For Residential Homes And Analyzing Water Stor- 
age Tank Size, in: Proc. ASME 2013 Int. Mech. Eng. Congr. Expo., ASME, 2013.

[19] D. E. Kalz, J. Wienold, M. Fischer, D. Cali, Novel heating and cooling concept employing rainwater cisterns and thermo-active building systems for a residential building, Appl. Energy 87 (2) (2010) 650-660. doi:10.1016/j.apenergy.2009.06.002.

URL http://linkinghub.elsevier.com/retrieve/pii/S0306261909002359

[20] G. Gan, S. B. Riffat, C. Chong, A novel rainwater-ground source heat pump - Measurement and simulation, Appl. Therm. Eng. 27 (2-3) (2007) 430-441. doi:10.1016/j.applthermaleng.2006.07.011.

URL http://linkinghub.elsevier .com/retrieve/pii/S1359431106002596

[21] X. Liu, L. Ni, S.-K. Lau, H. Li, Performance analysis of a multi-functional heat pump system in cooling mode, Appl. Therm. Eng. 59 (1-2) (2013) 253-266. doi:10.1016/j.applthermaleng.2013.05.032.

URL http://linkinghub.elsevier .com/retrieve/pii/S1359431113003955

[22] L. Ni, S. Lau, H. Li, T. Zhang, J. Stansbury, J. Shi, J. Neal, Feasibility study of a localized residential grey water energy-recovery system, Appl. Therm. Eng. 39 (2012) 53-62. doi:10.1016/j.applthermaleng.2012.01.031. URL http://linkinghub.elsevier.com/retrieve/pii/S1359431112000403

[23] BEopt, BEopt - NREL, Online (2012).

URL http://beopt.nrel.gov/

[24] H. W. Lee, J. W. Jones, Laboratory Performance Of An Ice-On-Coil, Thermal-Energy Storage System For Residential And Light Commercial Applications, Energy 21 (2) (1996) 115-130.

[25] K. Ismail, R. Moraes, A numerical and experimental investigation of different containers and PCM options for cold storage modular units for domestic applications, International Journal of Heat and Mass Transfer 
52 (19-20) (2009) 4195-4202. doi:10.1016/j.ijheatmasstransfer.2009.04.031.

URL http://linkinghub.elsevier.com/retrieve/pii/S0017931009003044

[26] R. Willis, Energy Efficient TES Designs for Commercial DX Systems, ASHRAE Trans. (2010) 147-156.

[27] R. Baetens, B. P. Jelle, A. Gustavsen, Phase change materials for building applications: A state-of-the-art review, Energy and Buildings 42 (9) (2010) 1361-1368. doi:10.1016/j.enbuild.2010.03.026.

URL http://linkinghub.elsevier.com/retrieve/pii/S0378778810001180

[28] M. Rutberg, M. Hastbacka, A. Bouza, TES for Residential Settings, ASHRAE J. (August) (2013) 92-94.

[29] C. O. Pedersen, U. S. A. Cerl, F. C. Winkelmann, EnergyPlus : Energy Simulation Program, ASHRAE J. 42 (2000) 49-56.

[30] J. D. Rhodes, W. H. Gorman, C. R. Upshaw, M. E. Webber, Using BEopt (EnergyPlus) with energy audits and surveys to predict actual residential energy usage, Energy Build. 86 (2014) 808-816. doi:10.1016/j.enbuild.2014.10.076.

URL http://dx.doi.org/10.1016/j.enbuild.2014.10.076

[31] A. R. I. Standard, Standard For Performance Rating Of Positive Displacement Refrigerant Compressors And Compressor Units, Tech. rep., Air Conditioning, Heating, and Refrigeration Institute; American National Standards Institute (2004).

[32] Emerson climate technologies, copeland compressor search (models: Criq-0290-pfv, zrd36kc-pfv, zr36k3-pfv) [cited April 28, 2014].

URL https://opi . emersonclimate.com/was . extension. opi . web/OPIServlet?action=compsearch

[33] Bristol compressor database (search models h21j363abc, h20c373abc) [cited April 28, 2014].

URL http://search. bristolcompressors.com/BCWF01.aspx 
[34] 2008 ASHRAE Handbook: HVAC Systems and Equipment.

[35] F. P. Incropera, D. P. DeWitt, Fundamentals of Heat and Mass Transfer 4th Ed., 4th Edition, Wiley and Sons, 1996.

[36] A. A. Bell, HVAC Equations, Data, and Rules of Thumb, McGraw-Hill, 2000.

[37] City of Austin Electric Rate Schdedules: Rates Approved September 11 2013, Effective October 12013 (2013).

URL http: //austinenergy . com/wps/wcm/connect/ab6d045c-643e-4c16-921f-c76fa0fee2bf/aeElec

[38] Weather analytics weather data files [cited April 28, 2014].

URL http://www . weatheranalytics . com/wa/products/data-weather-files/

[39] Nrel tmy3 database [cited April 28, 2014].

URL http://rredc.nrel.gov/solar/old_data/nsrdb/1991-2005/tmy3/by_state_and_city.html

[40] A. Faruqui, D. Ph, Direct Load Control of Residential Air Conditioners in Texas (2012). 


\section{Appendix A. BEopt Model Parameters}

Table A.4: The table below contains the relevant BEopt house model parameters used to generate the cooling load data used for the analysis.

\begin{tabular}{clll}
\multicolumn{3}{l}{ BEopt House Model Variables } \\
Parameter & Value & Units & Notes \\
\hline Conditioned Space & 1786 & sqft & single story \\
Glazing Area & 15 & $\%$ & Distributed equally on all sides \\
Duct Leakage & 15 & $\%$ & R6 ducts \\
Wall R Value & 11 & R-value & $2 \times 4$ stud, fiberglass batt, 1/2 OSB \\
Ceiling R Value & 11 & R-value & \\
Window U Value & 0.76 & U-value & Double Pane Clear Metal Frame \\
\hline
\end{tabular}




\title{
Appendix B. Compressor Information
}

\author{
Appendix B.1. Compressor Data
}

See Tables B.5 and B.6.

Table B.5: The five compressors selected are typical of compressors found in residential air conditioning units, and all provide nominally 3 -tons rated cooling capacity.

\begin{tabular}{lcccc}
\hline Designation & Type & $\dot{Q}_{\text {cooling rated }}[B T U]$ & $\dot{W}_{\text {c rated }}[k W]$ & Availability \\
\hline Compressor 1 & Scroll & 36,700 & 3.35 & Obsolete \\
Compressor 2 & Scroll & 36,900 & 3.29 & Available \\
Compressor 3 & Reciprocating & 36,000 & 3.15 & OEM \\
Compressor 4 & Scroll & 36,000 & 3.4 & Available \\
Compressor 5 & Reciprocating & 36,000 & 3.6 & Obsolete \\
\hline
\end{tabular}

\section{Appendix B.2. Compressor Scaling Calculation}

The modeled house had a nominal 3 ton cooling load $(36,000 \mathrm{BTU} / \mathrm{hr})$, and so compressors with similar nominal rated capacities were chosen. Two of the five compressors had rated cooling capacities slightly higher than the 3 ton rating, and were scaled to exactly 3 tons using Equation B.1. Equation B.1 gives the calculation of the multiplication factor, $C_{n o r m}$, used to scale the outputs of Equations 1 and 2 to scale the compressors' rated cooling capacity to $36,000 \mathrm{BTU} / \mathrm{hr}$ and the power demand to a corresponding adjusted value.

$$
\begin{array}{r}
C_{\text {norm }}=\frac{36,000[B T U / h r]}{\dot{Q}_{\text {cooling cap rated }}[B T U / h r]} \\
\dot{Q}_{\text {cooling cap, (scaled) })}=C_{\text {norm }} \times \dot{Q}_{\text {cooling cap } .} \\
\dot{W}_{c,(\text { scaled })}=C_{n o r m} \times \dot{W}_{c}
\end{array}
$$

The primary goal of the using the empirical compressor curves was to model real-world performance of a general model compressor, rather than a model for a specific compressor (hence re-scaling to a single common size). 


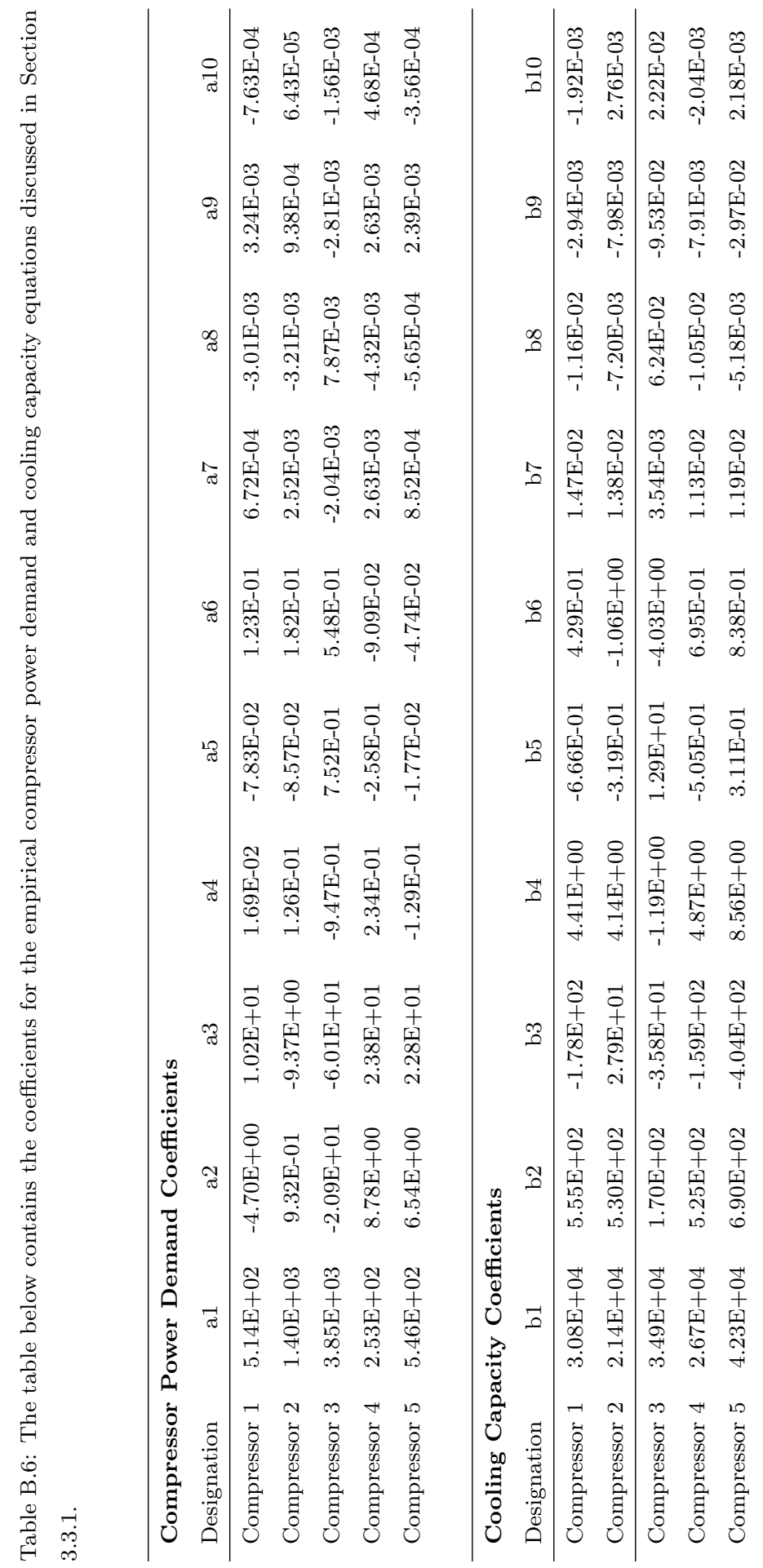

